\title{
From Personal Relationship to Psychological Ownership: The Importance of Manager-Owner Relationship Gloseness in Family Businesses
}

\section{Hang Zhu (朱沉), ${ }^{1}$ Chao C. Chen, ${ }^{2}$ Xinchun Li (李新春), and Yinghui Zhou (周影辉) ${ }^{3}$}

${ }^{1}$ Sun Yat-sen University, China, ${ }^{2}$ Rutgers University, USA and ${ }^{3}$ Shanghai University, China

ABSTRACT Integrating theories of psychological ownership and stewardship, and taking a relational perspective, we examine key antecedents and outcomes of professional managers' psychological ownership in Chinese owner-managed family businesses. We tested the model using a survey of 166 Chinese professional managers (one from each of 166 family businesses). We find that owner-manager relationship closeness at work mediates the effect of both the owner's benevolent leadership and owner-manager friendship ties on the manager's psychological ownership. Psychological ownership, in turn, is positively related to the manager's intention to stay and to stewardship behaviour. Theoretical and practical implications are discussed.

KEYwords benevolent leadership, Chinese family business, particularistic ties, psychological ownership, relationship closeness

从私人关系到心理所有权：家族企业中经理与企业主关系亲密度的重要性

摘要

融合心理所有权理论与管家理论，我们从关系的视角考察丁企业主管理的中国家族 企业中职业经理心理所有权的前因变量和结果变量，并运用对166位职业经理（铰个企业访 问一位经理）的问卷调查数据检验了本文的理论模型。我们发现企业主与经理的工作关系亲 密度中介了企业主仁慈领导和企业主与经理之间友谊关系连带对经理心理所有权的影响, 而 经理的心理所有权与经理的留职意向和管家行为正相关。我们讨论了上述结果的理论与实践 意义。

关揵词：仁慈领导，中国家族企业，特殊连带，心理所有权，关系亲密度 


\section{INTRODUCTION}

Psychological ownership is a powerful determinant of pro-organizational attitudes and behaviour by organizational members, especially those in family businesses (Corbetta \& Salvato, 2004; Pierce, Kostova, \& Dirks, 2001). One major source of such psychological ownership in family businesses is attributed to the union of ownership and management (Eddleston \& Kellermanns, 2007; Zahra, 2003). Financial ownership and management involvement by family members tend to generate strong psychological ownership, which alleviates agency problems and fosters stewardship behaviour (Davis, Schoorman, \& Donaldson, 1997; Miller \& Le-Breton Miller, 2005; Zahra, 2003). However, not all managers of family businesses are family members, and non-family managers may hold limited ownership or none at all. In such situations, using non-financial measures to foster psychological ownership in non-family members may be one of the key factors of business success (Barnett \& Kellermanns, 2006; Karra, Tracey, \& Phillips, 2006). While acknowledging the link between legal and psychological ownership, our research uses a relational perspective that explores the effects of non-legal and non-financial antecedents on non-family managers' psychological ownership (MPO). Drawing on insights from psychological ownership theory (Pierce et al., 2001) and stewardship theory (Davis et al., 1997), we examine how, in Chinese family businesses, close relationships at work, induced by the leadership style of the owner and owner-manager friendship ties, affects managers' psychological ownership, which in turn affects both the intention to stay and the stewardship behaviour of managers.

Through this study we seek to contribute to the research on family businesses in a number of ways. First, we examine the antecedents of psychological ownership by professional managers in a context in which the lack of actual ownership and blood relationship is most salient. In doing so, we contribute to psychological ownership theory by demonstrating the social and psychological antecedents as well as the effects of psychological ownership. Second, while previous studies have focused on family members and their relationships to owners (Davis, Allen, \& Hayes, 2010; Eddleston \& Kellermanns, 2007), our study examines the personal relationships between non-family managers and family owners, and the effect of this relationship on managers' psychological ownership and on their stewardship behaviour. Finally, this study contributes to the much-needed research on professional management in family businesses in China. Because of a tradition of suspicion toward and exclusion of non-family members (Redding, 1990), introduction of non-family professionals in Chinese family businesses presents challenges for retention and motivation (Carney, 1998; Zhang \& Ma, 2009). By bringing theoretical insights to this area of study, our findings have important implications for research into and the practice of family business governance and performance in general and in the Chinese context in particular. 


\section{THEORETICAL BAGKGROUND AND HYPOTHESES}

\section{Theory of Psychological Ownership}

Psychological ownership refers to a psychological state in which individuals feel as though a target (material or immaterial in nature), or a piece of that target, belongs to them (i.e., 'It is mine!') (Pierce et al., 2001: 14-15). The target of psychological ownership in an organizational context can broadly refer to the entire organization, or to a specific project or idea. Psychological ownership theory also further specifies three human motives that give rise to psychological ownership of a given target: efficacy and effectance, self-identity, and the desire to have one's own space (e.g., a home). The desire to have one's own place is conceived as an independent motive standing on its own, but in our view, it could also be a sub-motive of the first two primary motives.

Following the motivational rationale of psychological ownership, Pierce et al. (2001) proposed a number of antecedents of psychological ownership. The antecedents include the amount of employee control (over a given organizational factor such as a task or a decision), the degree of association and familiarity with a given organizational target (e.g., a team or a project) as well as the amount of time and energy investment in the target. Although Pierce and his colleagues examined the specific antecedents of psychological ownership beyond legal and financial ownership, they paid more attention to job-related factors than to social connections and interactions among organizational members (Pierce, Jussila, \& Cummings, 2009).

The positive organizational effects of psychological ownership include clear and balanced expectations of rights and responsibilities. The feelings of ownership are 'accompanied by a felt responsibility and a sense of burden sharing for the organization' (Pierce et al., 2001: 303). Specifically, the felt responsibilities include protecting, caring, and sacrificing on behalf of the organization (Pierce et al., 2001).

Because self-identity is a prominent motive from which psychological ownership is derived, we expect that psychological ownership is a more proximal antecedent to behavioural outcomes than are social identities, which are components of self-identity. Further, while psychological theorists have elaborated on individual motives that lead to psychological ownership, they have seldom specified organizational conditions and opportunities under which psychological ownership can be fostered. Thus when we examine non-family managers' psychological ownership in family businesses, the governance relationship proposed by stewardship theory is a pertinent and promising area.

\section{Stewardship Theory and MPO}

Davis et al. (1997) introduced the concept of stewardship into organizational governance and management. Stewardship is conceived of as a form of governance 
relationship with associated behaviours. In a stewardship relationship, managers are assumed and treated as caretakers of the organization who have the best interests of the organization at heart. As for behaviour, stewardship refers broadly to pro-organization behaviour such as sacrificing for the ongoing interest of the organization, protecting the organization's wealth, and enhancing the performance of the organization (Davis et al., 1997). These proposed stewardship behaviours are similar to and consistent with the behavioural outcomes of psychological ownership (Hernandez, 2012).

Davis et al. (1997) also proposed a set of psychological and situational antecedents of stewardship behaviour. Psychological antecedents include the strength of high-order needs, the level of intrinsic motivation, and the level of identification with and commitment to the organization. Situational antecedents include groupor collective-oriented organizational culture and a climate of trust.

Stewardship theory (Davis et al., 1997) provides additional insight for psychological ownership. First, the notion of stewardship relationships directs attention toward the nature of owner-manager relationships. In family businesses, the owner-manager's leadership style and particularistic ties are informal governance that forms the stewardship relationship. Second, organizational identification (discussed below), a key antecedent of stewardship behaviour, is also an important motive that leads to psychological ownership.

In general, psychological ownership theory (Pierce et al., 2001) and stewardship theory (Davis et al., 1997) inform and complement each other, pointing to social and relational antecedents. In a chain of influence, these antecedents generate relationship closeness and identification, leading to psychological ownership, which then stimulates stewardship behaviour. In the following sections, we theorize that: 1) both an owner's benevolent leadership style and an owner-manager's friendship ties affect MPO through the mediation of relationship closeness; and 2) relationship closeness affects managers' stewardship behaviour and intention to remain with the organization through the mediation of MPO.

\section{Benevolent Leadership, Owner-Manager Relationship Closeness at Work, and MPO}

In the structure of family businesses, especially among Chinese firms, the executives tend to rely on paternalistic leadership, of which benevolent leadership style is one of three components (Chen \& Farh, 2009; Farh \& Cheng, 2000). Benevolent leadership displays holistic care and concern for the welfare of the subordinate and his or her family. Paternalistic leadership theory proposes that benevolent leadership engenders feelings of indebtedness and obligation from subordinates, which motivate in-role and extra-role performance (Farh \& Cheng, 2000; Wu, Huang, Li, \& Liu, 2011). By cultivating feelings of indebtedness and obligation, benevolent leadership inspires MPO by creating a close work relationship with the owner. 
Relationship closeness at work is the psychological bond developed between colleagues, and manifests itself in positive job-related behaviours such as helping, encouragement, honest feedback, and communication (Chen \& Peng, 2008).

Psychological ownership theory posits that self-identity motives lead to psychological ownership - to the extent that an individual is familiar with, associates with, and is identified with a target (Pierce et al., 2001). We argue that the concept of owner-manager relationship closeness captures such familiarity, association, and identification. Benevolent leadership inevitably involves more personal and family interactions between the manager and the owner, so that the manager is drawing closer-literally and psychologically - to the owner. Furthermore, by demonstrating care and concern for the welfare of the non-family manager and his or her family, the owner signals a long-term relationship, creating in the manager feelings of personal and family inclusion (Chen, Eberly, Chiang, Farh, \& Cheng, forthcoming). Such feelings of inclusion enhance the manager's relationship closeness with the owner, further solidifying her or his personal attachment to the owner (Chen, Friedman, Yu, Fang, \& Lu, 2009), and organizational identification with the family business (Karra et al., 2006). Such attachment and identification lead to psychological ownership (Pierce et al., 2001). In summary, we expect a positive correlation between the owner's benevolent leadership and the non-family manager's psychological ownership of the family business. It is not benevolent leadership behaviour per se, but rather the personal owner-manager relationship closeness generated by such behaviour, which accounts for the positive correlation. We therefore hypothesize:

Hypothesis 1: Ozener-manager relationship closeness at woork will mediate the positive relationship between the benevolent leadership style of the owner and the non-family manager's psychological ownership.

\section{Particularistic Ties, Owner-Manager Relationship Closeness at Work, and MPO}

The term 'particularistic ties' refers to shared social identities that often serve as the basis of Chinese guanxi (Farh, Tsui, Xin, \& Cheng, 1998; Hwang, 1987). Kinship, birthplace, alma mater, and personal friendships are examples of particularistic ties among co-workers of an organization. In family businesses, there are two main types of particularistic ties: kinship ties (relatives of the owner, excluding immediate family members) and friendship ties (e.g., former classmates, former comrades-in-arms, and current friends) between the owner and the manager. In this study we focus on friendship ties, holding constant kinship ties. Owners may hire managers with kinship ties out of a sense of family obligation rather than on the basis of merit and qualifications. Consequently, the impact of kinship relations on relationship closeness and MPO may be ambiguous. Controlling for kinship ties would remove the confounding effect it could have on friendship ties. 
A number of reasons support the view that non-family managers who have friendship ties with the owner are more likely to develop feelings of psychological ownership than are managers who have a mere work relationship without such particularistic ties to the owner. First, these managers may enjoy an insider status (Chen \& Aryee, 2007). In Hwang's (1987) guanxi categorization, friends are substantively different than mere acquaintances, because the former are seen as 'pseudo-family' members. The insider (family) status is therefore a powerful social identity that connects the manager with the owner and the family business (Chen et al., 2009; Yeung, 2000). Second, managers with friendship ties to the owner have an advantage over other managers without such ties in terms of having more opportunities to interact with the owner for both work- and nonwork-related affairs. To the extent that such interactions involve both affective, family-like exchanges outside work and instrumental exchanges at work, managers with friendship ties to the owner are more likely to develop personal identification with the owner and organizational identification with the family business (Luo, 2011). Finally, managers hired on the basis of friendship ties (such as former classmates) are likely to have been hired based not only on necessary expertise, but also on aspirations and values that are shared with the owner (Chen, Chen, \& Xin, 2004).

Summarizing the above discussion, we propose the following hypothesis:

Hypothesis 2: Owoner-manager relationship closeness at work will mediate the positive relationship between the non-family manager's friendship ties to the owener and the manager's psychological ownership.

\section{The Mediating Effect of Psychological Ownership}

In the above hypotheses, we focus on the central role of the owner-manager relationship that serves to connect the owner's leadership style and the ownermanager friendship ties to MPO. We argue that, although we expect a positive correlation between relationship closeness and pro-organizational attitude and behaviour, which are the ultimate outcomes desired by the company, it is not relationship closeness per se that accounts for the variation in managerial outcomes. Rather, it is due to MPO, a psychological mechanism that is morc proximal to the outcome variables.

MPO, while entailing organizational identification, also represents a 'felt responsibility and a sense of burden sharing' (Pierce et al., 2001: 303). Hence MPO explicitly captures a vicarious owner attitude, making it most potent in motivating pro-organizational attitudes and stewardship behaviour (Hernandez, 2012; Pierce et al., 2001). Managers who have stronger psychological ownership are more likely to be committed to the organization (Bernhard \& O'Driscoll, 2011; Van Dyne \& Pierce, 2004) and to display stewardship behaviour (Pierce et al., 2001; Wasser- 
man, 2006). In summary, although both relationship closeness at work and MPO are positively related to pro-organizational attitudes and behaviour, MPO results from relationship closeness at work, and hence mediates the latter's effect on the outcomes. We therefore hypothesize:

Hypothesis 3: The non-family manager's psychological ownership will mediate the positive association between relationship closeness at work and the non-family manager's stewardship behaviour.

Hypothesis 4: The non-family manager's psychological owemership will mediate the association between relationship closeness at work and the non-family manager's intention to stay.

A summary of the hypotheses can be seen in Figure 1.

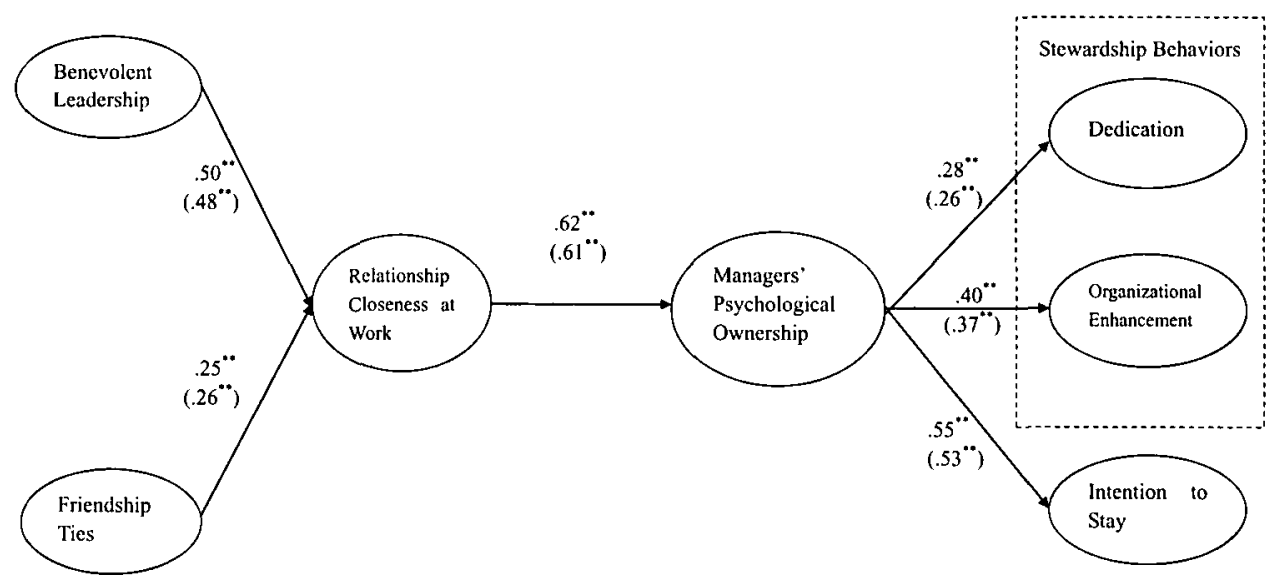

Figure 1. Hypothesized model and final model (model 1)

Note: Standardized estimates are shown, and the values in the parentheses are standardized estimates of model 6 (with a common method factor). ${ }^{*} \mathrm{p}<0.05{ }^{* *} \mathrm{p}<0.01$.

\section{METHODS}

\section{Sample and Procedure}

We targeted firms that were controlled (with more than 50 percent ownership) by a family and managed by the owner. One executive manager from each targeted firm was invited to participate. In terms of requirements, the managers had to have no ownership in, or have only a minority share of, the family business, yet had personal interactions with the owner at work. Those managers who were members of the owner's nuclear family were excluded. We invited a total of 256 managers who satisfied our criteria to participate in the study (some with assistance from human resources [HR] managers). Among those invited, 235 agreed and 21 
declined. However, of those who agreed to participate, 69 provided personal and company information but didn't complete the rest of the survey. We used the complete data from 166 respondents (64.8\%) for testing our hypotheses. We used the partial data from 69 respondents to assess non-respondent bias by comparing company age, employee number, fixed assets, manager's age, gender, education, and tenure, between the 166 full participants and the 69 partial participants. The results of one-way ANOVA showed no significant difference $(p>0.1)$ on any of these variables between the two groups.

The study respondents came from two sources and all met the above sampling requirements. Of the total group, 71 were part-time MBA and Executive Development Program (EDP) students at a business school in southern China, and 95 were managers who were recruited with the help of HR managers from Guangzhou and Shantou in the southern province of Guangdong and in the metropolitan city of Tianjin in northern China. The MBA and EDP participants completed the survey in their classrooms and handed them to the first author, while the managers who were recruited outside the school completed the surveys in their own time and mailed them to the assisting HR managers. The average age of the firms was 10 years (standard deviation was 5.9); the average number of employees per firm was 650 (standard deviation was 1506), with $80.1 \%$ of the firms having fewer than 500 employees; 33.7 percent had fixed assets over RMB 50 million. The sample managers had an average tenure of 4.47 years with standard deviation of $3.0 ; 46.4$ percent were 30 to 40 years old; 72.3 percent were male; and 54.2 percent of the managers had received an undergraduate degree. We used one-way ANOVA to compare the means of all study variables and control variables of the two sub-samples (program participants and managers recruited from companies), and there was no difference $(p>0.1)$ in these variables except for the educational level, which we controlled in the later SEM analyses.

\section{Measures}

Benevolent leadership was measured by five items from the short five-item scale used by Cheng, Chou, Huang, Farh, and Peng (2003). The subjects indicated the extent to which each statement described the leadership style of the owner manager (e.g., 'My boss will help me when I have an emergency'). Cronbach's alpha for the scale was 0.87 .

Particularistic ties. The respondents were asked to indicate whether or not they had various ties with the owner, such as relatives, former classmates, former comradesin-arms, and friends. These ties were further grouped into two dummy variables: friendship ties (if the non-family manager was a former classmate, former comradein-arms, or friend of the owner) and kinship ties (consanguinity within three generations) with acquaintances as the omitted category. 
Relationship closeness at work consists of seven items adapted from a relationship closeness scale developed by Chen and Peng (2008). Of the original nine items, two non-work-related items were excluded. Each subject evaluated his or her current interaction with the owner at work (e.g., 'We understand each other at work'). Cronbach's alpha for the scale was 0.92 .

Managers' psychological owerership consists of seven items adapted from Van Dyne and Pierce (2004). The subjects described their feelings toward the firm. A sample item is 'I sense that this is my company'. Cronbach's alpha for the MPO scale was 0.93 .

Stewardship behaviour. We developed a measure of stewardship behaviour because the existing measure by Davis, Frankforter, Vollrath, and Hill (2007) was unavailable to us at the time we carried out the study. In addition, the Davis et al. measure relates to general stewardship perception rather than specific stewardship behaviour. Following Davis et al.'s (1997) definition that stewardship behaviour is proactive behaviour that maximizes organizational welfare, we searched for items that: 1) are targeted at the whole organization, as opposed to organizational subunits (Hernandez, 2012); and 2) are typically performed by mid- and high-level managers rather than rank-and-file employees. We selected or generated items in two ways. First, we chose six organizational citizenship behaviour (OCB) items from Farh, Zhong, and Organ (2004). The scale developed by Farh et al. (2004) is an appropriate source because it has gone through rigorous validation tests in Chinese organizations, and the selected items are conceptually consistent with Davis et al.'s (1997) description of managers' stewardship behaviour. The second source of items was family business managers. Using the focus group discussion format, we sought input from 15 family business managers, who commented positively on the appropriateness of Farh et al. 's organization-directed OCB items, and suggested five additional items that they considered to be examples of exemplary stewardship behaviour of non-owner managers.

The 11 items were subject to exploratory factor analysis (EFA) in a pilot study (described in the Results section); low and cross-loading items were deleted. The selected items are listed in Appendix 2. Two factors emerged from the EFA procedure, which we labelled 'Dedication', and 'Organizational Enhancement', with Cronbach's alphas being 0.77 and 0.80 , respectively.

Intention to stay was measured by reverse scoring the three items from Konovsky and Cropanzano (1991). A sample item is 'How likely is it that you will look for a job outside of this organization during the next year?' Cronbach's alpha was 0.85 .

Control variables. We measured legal owemership by determining whether the nonfamily manager was a shareholder, and whether he or she had profit-sharing rights with the owner. Kinship ties were coded by whether the manager had relative 
ties with the owner. We also controlled for individual backgrounds - gender, age, education, and tenure - and company variables of firm size (the number of employees) and firm age.

All scales except stewardship behaviour are listed in Appendix 2. Scales originally written in English, including psychological ownership and intention to stay, were translated from English into Chinese through the back translation method (Brislin, 1980). Benevolent leadership, relationship closeness at work, and MPO were rated on seven-point scales ranging from 1, 'most disagree', to 7, 'most agree'. Stewardship behaviour was evaluated on seven-point scales ranging from 1, 'most unlikely', to 7, 'most likely'. The items of intention to stay had three different anchors, depending on the wording of the question. All information was provided by the survey participants. Alpha reliabilities and AVE values for all survey measures used in this study are provided on the diagonal of Table 1 (the numbers in parentheses).

\section{RESULTS}

\section{Pilot Study Testing Measurements}

Prior to collecting data for testing the hypotheses of the study, we conducted a pilot study to test the reliability and validity of the stewardship behaviour measure because some of the items were newly developed for the current study. The pilot sample consisted of 187 part-time MBA students and EDP participants from a business school in southern China. All of them were managers working in family businesses. They completed the survey forms in a classroom and handed them to the first author.

All 11 stewardship behaviour items were subject to EFA, using the principal components method with a varimax rotation. Two factors with eigenvalues greater than 1 emerged and were labelled 'Organizational Enhancement' and 'Dedication'. We deleted four items with low or cross-loadings. All four deleted stewardship behaviour items were supplied by the managers, whereas all of the previously validated items from Farh et al. (2004) had satisfactory loadings. In Appendix l, we listed both retained and excluded items. Cronbach's alpha for each scale was computed, and all of them exceeded 0.80 . The loadings of the remaining seven items ranged from 0.75 to 0.84 . These items formed the measure consisting of five from previous research and one from the managers. This measure was used in the main study and would be subject to confirmatory factor analysis.

\section{Evaluation of Measurements in the Main Study}

Using LISREL 8.72 (Jöreskog \& Sörbom, 2005), we ran a series of confirmatory factor analytic (CFA) tests of alternative measurement models against our 


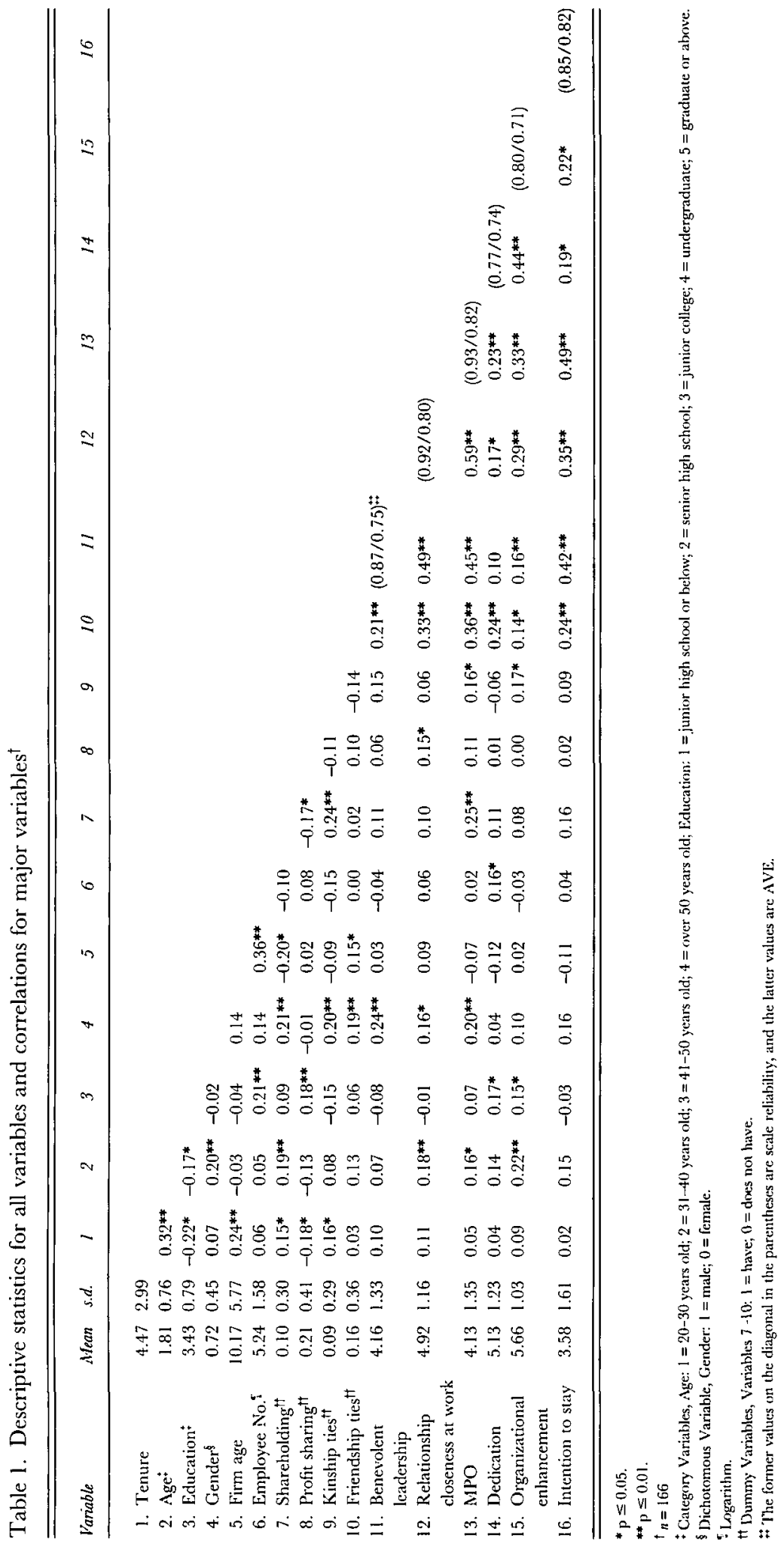

(C) 2012 The Intcrnational Association for Chinese Management Research 
hypothesized six-factor model (benevolent leadership, relationship closeness at work, MPO, dedication, organizational enhancement, and intention to stay). The CFA provided a more rigorous assessment of the discriminant validity of the modified and new measures in the study. The six-factor model was tested against five alternative factor models: measurement model 2 , in which all variables were collapsed into one factor; measurement model 3, in which the three outcome variables were combined into one factor; measurement model 4 , in which MPO was combined with three outcome variables into one factor; measurement model 5 , in which relationship closeness at work and MPO were combined into one factor; and measurement model 6 , in which benevolent leadership and relationship closeness at work were collapsed into one factor. All of the alternative factor models were significantly different from the six-factor model $\left(\Delta \chi^{2}[15]=1769.8, p<0.01\right.$; $\Delta \chi^{2}[9]=397.9, \mathrm{p}<0.01 ; \Delta \chi^{2}[12]=632.3, \mathrm{p}<0.01 ; \Delta \chi^{2}[5]=787.7, \mathrm{p}<0.01 ;$ $\left.\Delta \chi^{2}[5]=371.0, \mathrm{p}<0.01\right)$. The fit indices of these measurement models, as well as relevant chi-square difference tests, are reported in Table 2. As can be seen in Table 2, the goodness of fit was not acceptable for any of the five alternative factor models, but was acceptable for the hypothesized six-factor model $\chi^{2}=665.15$, d.f. $=362, \mathrm{p}<0.01$ ). All indicators loaded significantly on their respective constructs, with standardized loadings exceeding 0.61 . These results support the sixfactor measurement model.

Furthermore, to test whether dedication and organizational enhancement are aspects of stewardship behaviour, we conducted a CFA test for the two sub-measurements (measurement model 7 , also shown in Table 2). The result $\left(\chi^{2}=23.6\right.$, d.f. $\left.=13, p<0.05\right)$ was acceptable. All indicators loaded significantly on their respective constructs, with standardized loadings exceeding 0.61 . These results supported the two-factor measurement model.

According to Fornell and Larcker (1981), a more stringent criterion of discriminant validity is that across all possible pairs of constructs the average variance extracted (AVE) for each construct should be greater than the squared latent correlation between the pair of constructs. We calculated the square root of AVE for each construct (in the diagonal in parentheses of Table 1) and found that the square root of AVE for each construct was larger than any of the correlations in the column or the row in which the construct was found. These results lend strong support for the discriminant validity of the constructs in our study.

\section{Descriptive Statistics}

Means, standard deviations, Cronbach's alpha coefficients, and correlations of the variables are illustrated in Table 1 . All significant correlations were in the expected direction. Benevolent leadership $(r=0.49)$ and friendship ties $(r=0.33)$ were positively correlated with relationship closeness at work, which was positively 


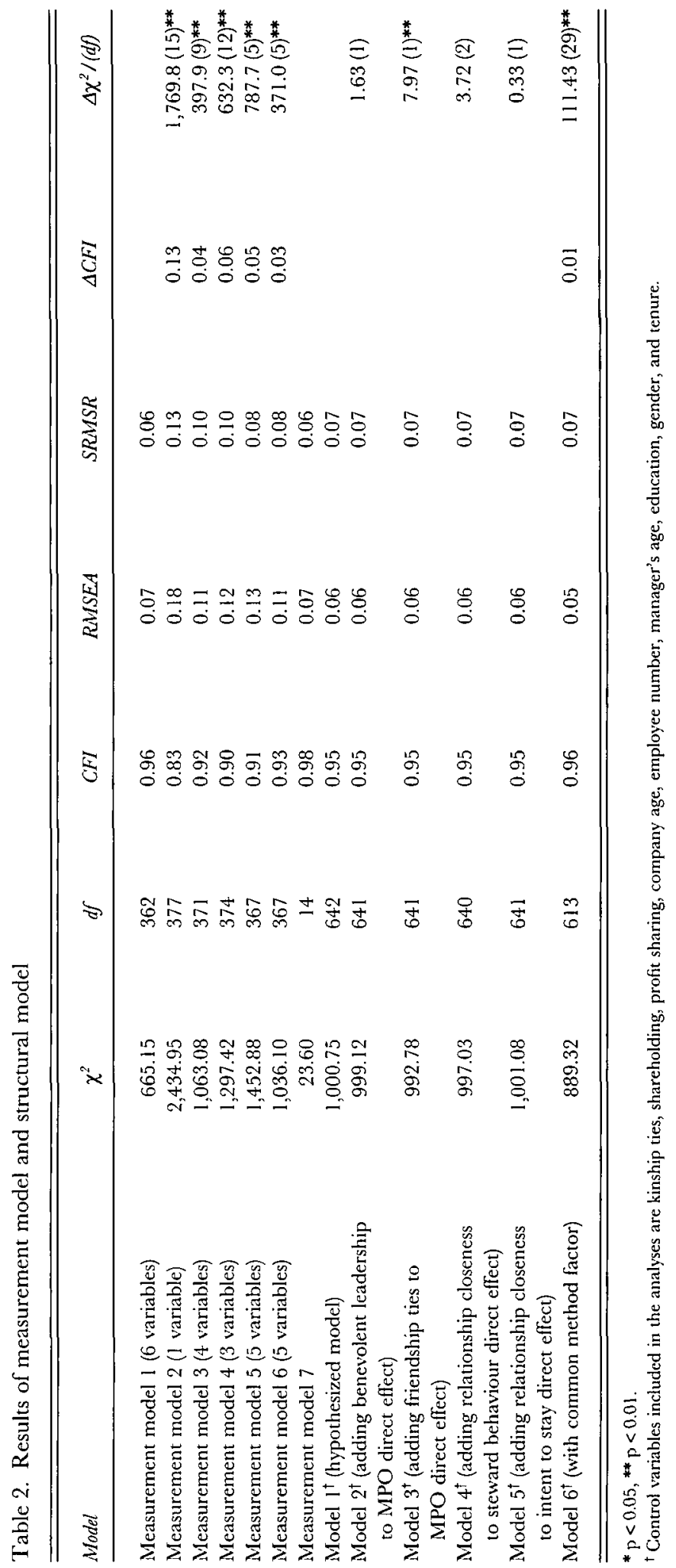

(C) 2012 The International Association for Chinese Management Research 
correlated with MPO $(\mathrm{r}=0.59)$. MPO was positively correlated with dedication and organizational enhancement $(r=0.23,0.33)$, as well as intention to stay $(r=0.49)$. As indicated by means of the dummy variables in Table $1,10 \%$ of the respondents held company shares, $21 \%$ had profit sharing with the company, $9 \%$ reported kinship ties to the owner, and $16 \%$ reported friendship ties to the owner.

\section{Model Testing}

For testing mediation hypotheses, we sought the best-fitting model among a set of nested alternatives before examining parameter estimates (Anderson \& Gerbing, 1988). In these structural models, we included as control variables those factors that may influence managers' psychological ownership, such as kinship ties, shareholding, profit sharing, company age, employee number, manager's age, education, gender, and tenure. The lower panel of Table 2 reports the fit indices of these models, as well as relevant chi-square difference tests. Model 1 is the hypothesized model. From these, we made four comparisons. First, we compared model 1 with the same model to which we added the path from benevolent leadership to MPO (model 2). Thus, we were comparing the hypothesized full mediation to an alternative partial mediation for benevolent leadership, relationship closeness at work, and MPO. The comparison showed a statistically significant chi-square difference $\left(\Delta \chi^{2}[1]=1.63, \mathrm{p}>0.1, \Delta \mathrm{CFI}<0.01\right)$. However, according to Cheung and Rensvold (2002), $\Delta \mathrm{CFI}=0.01$ or less means that the difference between the models does not exist. Adopting the stricter criterion, we concluded that the addition of the direct link between benevolent leadership and MPO did not add significantly to the model.

Next, we compared model 1 with the same model to which we added the path from friendship ties to MPO (model 3). This comparison involved the hypothesized fully mediated model and an alternative partially mediated model for friendship ties, relationship closeness at work, and MPO. Although the chi-square difference was statistically significant $\left(\Delta \chi^{2}[1]=7.97, \mathrm{p}<0.01\right)$, the $\Delta \mathrm{CFI}<0.01$. Adopting the stricter criterion recommended by Cheung and Rensvold (2002), we retained model 1 , the fully mediated model.

Third, we compared model 1 with the same model but added direct paths from relationship closeness at work to two aspects of stewardship behaviour (model 4). Because models 1 and 4 were not significantly different $(\Delta \mathrm{CFI}<0.01$, $\Delta \chi^{2}[2]=3.72, p>0.10$ ), we retained model 1 because it was more parsimonious. Finally, we compared model 1 with the same model but added paths from relationship closeness at work to intention to stay (model 5). Because models 1 and 5 were not significantly different $\left(\Delta \mathrm{CFI}<0.01, \Delta \chi^{2}[1]=0.33, \mathrm{p}>0.50\right)$, we retained model 1 , the more parsimonious model. All standard estimates of path coefficients of model 1 are shown in Figure 1. 
With regard to hypothesis testing, we found that benevolent leadership was positively related to relationship closeness at work $(\beta=0.50)$, and the latter was positively related to MPO $(\beta=0.55)$. Considering the results of model comparison, Hypothesis 1 , the mediation hypothesis, is supported. Friendship ties relates positively to relationship closeness at work $(\beta=0.25)$, and the latter was positively related to MPO $(\beta=0.55)$. These findings support Hypothesis 2.

MPO relates positively to all three outcome variables of dedication, organizational enhancement, and intention to stay, respectively $(\beta=0.28,0.40$, and 0.55 , respectively). No significant direct effect of relationship closeness at work was found on stewardship behaviour or intention to stay. These results therefore support Hypotheses 3 and 4 . Of the controlling variables, shareholding is positively related to MPO $(\beta=0.16)$, but other variables have no significant effect.

For additional tests of these mediation effects, we conducted Sobel's (1982) tests. Directly assessing the significance of indirect effects was in line with recent recommendations by several scholars for looking at mediated effects (MacKinnon, Lockwood, Hoffman, West, \& Sheets, 2002). Results for our final model were as follows: all five indirect effects were significant at $0.05 \mathrm{p}$ levels (friendship ties $\rightarrow$ $\mathrm{MPO}=0.16$, benevolent leadership $\rightarrow \mathrm{MPO}=0.31$, relationship closeness at work $\rightarrow$ dedication, organizational enhancement, and intention to stay $(r=0.17$, 0.25 and 0.34). These results support Hypotheses 1 and 2 with reference to relationship closeness at work, mediating the positive effects of benevolent leadership and friendship ties on MPO. Hypotheses 3 and 4, with reference to MPO mediating the positive effect of relationship closeness at work on stewardship behaviour and intention to stay, are supported.

\section{Assessment of the Effect of Common Method Biases}

According to the recommendation of Podsakoff, Mackenzie, Paine, and Bachrach (2000), we re-estimated model 1 with a 'common method' first-order factor added to the indicators of all evaluation constructs (model 6), to assess the potential effect of common method biases on the structural parameter estimates. A comparison of standardized parameter estimates, when common method variance was and was not controlled for, revealed that all hypothesized relationships were significant even with this bias controlled (See Fig. 1).

\section{DISCUSSION}

All four hypotheses were fully supported in this study. First, manager-owner relationship closeness at work fully mediated the effect of both owners' benevolent leadership and manager-owner friendship ties on managers' psychological ownership. Furthermore, MPO had a positive effect on stewardship behaviour and intention to stay. The full mediation effect of relationship closeness at work high- 
lighted the social identification mechanisms through which owner leadership style and owner-manager friendship ties influence managers' psychological ownership in Chinese family businesses.

Although not our research focus (as it is used as a control variable in our study), the lack of significant effect of kinship ties on either psychological ownership or the outcome variables (the indirect effects were tested by Sobel's test too) is unexpected and is inconsistent with the prevailing literature on how blood relationships increase personal and organizational attachment and reduce opportunism (Davis et al., 2010). We attribute the lack of positive effect of kinship ties to the fact that they are significantly related to financial shares $(r=0.24, p<0.01)$ and the latter did show significant effects on psychological ownership and the outcome variables. (According to the results of Sobel's test, only the indirect effect of shareholding on dedication is significant at the 0.1 level, and others are significant at the 0.05 level.) Nevertheless, the different effects of kinship ties and friendship ties are remarkable and suggest that kinship relationships on average may not on their own breed additional psychological ownership beyond that of financial ownership.

\section{Contributions}

The first contribution of our study, specifically related to our research on psychological ownership, lies in the social relational perspective. Although research in the field has begun to examine non-legal and non-financial antecedents of psychological ownership, the literature is still silent on the influence of personal and social relationships between family and non-family members. Controlling for legal ownership and profit-sharing, we found a significant impact of owners' benevolent leadership and manager-owner friendship ties on MPO. More importantly, we found evidence for the psychological pathways that connect the social antecedents to non-owner managers' psychological ownership. Such a mediation effect of relationship closeness at work is more striking than the non-mediation effect for financial shareholding. It suggests that cultivating close owner-manager work relationships is the key to fostering psychological ownership in non-family related, professional managers.

The second contribution of our study is uncovering the antecedents of MPO, beyond financial ownership and family relationships in family businesses. The family businesses literature has paid less attention to relationship development outside kinship networks, with the underlying assumption being that the deep relationship embedded in kinship ties is hard to duplicate elsewhere. However, our study clearly demonstrates the possibility of friendship ties providing a similar effect as that of kinship ties on psychological ownership. This means that even when owners have no blood relationship with managers, the owners can apply benevolent leadership and can develop friendship ties to enhance MPO through the development of close working relationships with these non-family managers. These 
findings are especially meaningful for Chinese family businesses, which have been found to be limited in size mainly due to low levels of trust between owners and non-family members (Fukuyama, 1995; Redding, 1990).

The third contribution of the study is the integration of psychological ownership theory with stewardship theory. Although scholars have proposed the link between psychological ownership and stewardship behaviour (Corbetta \& Salvato, 2004; Hernandez, 2012), there is little empirical research substantiating such linkage. Our study not only provides empirical support for the correlation between psychological ownership and stewardship behaviour, but also shows how organizational factors such as executive leadership style affect managers' stewardship behaviour through the mediation of psychological ownership.

A final contribution of this study lies in its potential to stimulate cross-cultural studies. Our findings are consistent with previous research that demonstrates the significance of interpersonal relationships in societies based on Confucianism (Chai \& Rhee, 2010; Hui, Lee, \& Rousseau, 2004). The question arises, then, of whether the findings generalize to family firms in other emerging economies that have traditions of collectivism, or to those in Western economies with cultural traditions of individualism. Future studies could productively compare owner leadership styles and owner-manager relationships in family firms across nations and cultures.

\section{Limitations}

One major limitation of the current study is that the data used for testing the models are cross-sectional and were collected from the same source, namely managers. Thus the causal effects between the independent and dependent variables in our model need future replication with a longitudinal or an experimental design. In an attempt to decrease the same-source bias, we collected more 'objectively' verifiable data such as kinship and friendship ties, which allowed us to examine their relationship with the more subjective measure of relationship closeness, but the risk of common method variance still exists. A second major limitation is that the conception and the measurement of stewardship behaviour need to be improved. Our measure of stewardship behaviour is based partly on Davis et al.'s umbrella definition and partly on input from managers. However, Hernandez (2012) conceptualized stewardship behaviour as being distinct from organizationally directed $\mathrm{OCB}$, in that stewardship behaviour emphasizes those behaviours that are targeted toward enhancing the long-term, intergenerational well-being of the organization. Future empirical research can add stewardship items that are targeted at the long-term interests of the organization. Alternatively, in view of the difficulty in obtaining specific yet comprehensive stewardship behaviour, perceptional or reputational measures may be useful. For example, summary questions can be asked about the extent to which a focal manager acts like an excellent 
steward. Last, we derived our hypotheses about the effects of leadership styles and particularistic ties on the basis of relational and organizational identities. While we emphasized their similarity, it is possible that these are independent mechanisms. Future research could include social identity to test its effects above and beyond relationship closeness.

\section{Future Research Implications}

Despite these limitations, the current study has important research implications. In a society lacking strong institutional trust, developing stewardship relationships between family owners and professional managers is a challenging but necessary task for growing Chinese family businesses (Chua, Chen, Kirkman, Li, Rynes, \& Gomez-Mejia, 2012; Zhang \& Ma, 2009). Consistent with psychological ownership and stewardship theories, our study demonstrates the potential for fostering stewardship behaviour among non-family members, managers and lower-level employees alike, through cultivating psychological ownership. To stimulate future studies, we indentify a few additional ways to generate psychological ownership of non-family employees. First, the antecedents on which we focused in this study (namely, benevolent leadership style and owner-manager friendship ties) affect psychological ownership primarily by satisfying the managers' self and social identity motives. Future research can explore antecedents that target the efficacy and effectance motives of the managers. For example, empowering leadership (Zhang \& Bartol, 2010) and developmental leadership (Manz \& Sims, 1987) could generate feclings of efficacious control and influence over the work environment. Second, leadership style and owner-manager relationships, while having clear organizational implications, are still rooted in the personal and interpersonal actions of the owner and the managers; future research could explore organizational factors. Examples include an organizational culture valuing egalitarianism, participation, and open communication vs. hierarchy, centralization, and secrecy, and an employment relationship characterized as involving long-term social exchanges vs. short-term economic exchanges (De Jong, Schalk, \& De Cuyper, 2009). Parallel to these more pervasive and institutionalized practices are organizational-level psychological antecedents such as institutional trust and organizational identification (Li, Bai, \& Xi, 2012). These institutional level antecedents may substitute, supplement, or enhance the personal or dyadic-level antecedents. More importantly, institutional antecedents may exert broader influence than interpersonal antecedents to the extent that the owner cannot develop close relations with each and every manager or employee. Institutional antecedents may also have an advantage over the personal characteristics of the owner because once established the former is less susceptible to problems associated with leader succession or change. Finally, future research can investigate individual characteristics of the professional manager and the person-organization fit (Chatman, 1989) between the professional manager 
and the family business in terms of values, career aspirations, and the stages of personal and organizational life.

\section{Managerial Implications}

Our study carries meaningful implications for family businesses. First, while legal ownership sharing may be the classic means of fostering identification, MPO, and stewardship of non-family members, family business owners have social and relational means available to them to foster psychological ownership and to motivate stewardship behaviour. Second, our study shows that the family business ownerexecutive can capitalize not only on current friendship ties, but also on her or his own leadership style, to enhance non-family managers' psychological ownership. Third, it is not the friendship ties, or the leadership style per se, but rather the actual owner-manager work relationship quality that generates managers' psychological ownership. The key is in the ways that personal and organizational resources can be used to cultivate personal and social identification, and to develop a sense of autonomy and efficacy so that the key non-family members of the organization feel as if they, too, own the family business.

\section{CONGLUSION}

Although Chinese family business research lauded kinship ties as an effective means for controlling managerial opportunism (Chua et al., 2012), this study highlights the psychological ownership of non-family members, especially those in managerial positions. It appears that financial capital and social capital affect psychological ownership differently. Substantive financial stakes in a family business, be they held by family or non-family members, may directly generate psychological ownership, which in turn will promote stewardship behaviour. Social/ guanxi tics, on the other hand, generate psychological ownership indirectly through the cultivation of close work relationships. It is also worth pointing out that our study suggests that friendship ties can have an advantage over kinship ties in that the former has more capacity than the latter to foster psychological ownership above and beyond the direct effect of financial ownership. It goes without saying that stewardship in family business is most likely when owners offer their managers both a financial stake and a long-term employment relationship that fosters strong social identification with the organization as well as with the owner.

\section{NOTES}

Financial support from Natural Scicnce Foundation of China (project No. 71072093 and 71172167), the Fundamental Research Funds for the Central Universities (project No. 13wkpy17), and the 985 Project (the innovation base for Chinese family business research) from Sun Yat-scn University are greatly acknowledged. We thank Professor Anne Tsui, Professor Soon Ang, and three anonymous reviewers for their helpful comments. 


\section{APPENDIX 1}

EFA result of the pilot study

The items of the measurements

Factor

$1 \quad 2$

Stewardship Behaviour (SB)

Dedication

1. Taking work scriously even if it is not part of the performance appraisal ${ }^{\dagger}$

$0.240 \quad 0.431$

2. Voluntarily working overtime without financial compensation

$0.029 \quad 0.809$

3. Doing things that are not required by the job but are beneficial to the

$0.376 \quad 0.761$ company

4. Voluntarily taking on extra tasks without being asked to

$\begin{array}{ll}0.286 & 0.757\end{array}$

5. Overcoming obstacles in performing tasks ${ }^{\dagger}$

$0.536 \quad 0.489$

Organizational Enhancement

6. Trying one's best to save costs for the company ${ }^{\dagger}$

$0.619 \quad 0.423$

7. Making suggestions beneficial to the growth of the company

$0.836 \quad 0.188$

8. Eliminating employee behaviours that may hurt the interests of the company

$0.816 \quad 0.228$

9. Eliminating unfair phenomena in the company ${ }^{\dagger}$

$0.540 \quad 0.196$

10. Voluntarily recommending products and services of the company to outsiders

11. Using personal social network to help the company

$0.831 \quad 0.180$

$0.747 \quad 0.271$

\section{Note:}

Extraction Mcthod: Principal Component Analysis; Rotation Method: Varimax with Kaiser Normalization.

t The deleted items.

\section{APPENDIX 2}

\section{Items of the benevolent leadership scale, guanxi closeness at work scale, psychological ownership scale, and intention to stay scale}

\section{Benevolent Leadership}

1. Beyond work relations, he/she expresses concern about my daily life.

2. He/She ordinarily shows a kind concern for my comfort.

3. He/She will help me when I'm in an emergency.

4. He/She takes very thoughtful care of subordinates who have spent a long time with him/her.

5. He/She takes good care of my family members as well.

\section{Guanxi Closeness at Work}

1. We understand each other at work.

2. We support each other at work.

3. We keep the other party's interest in mind at work.

4. We respect each other's point of view at work. 
5. We can fully communicate about the problems at work.

6. We trust each other at work.

7. We always take other's interest in consideration at work.

\section{Psychological Ownership}

1. This is my organization.

2. I feel that this company is ours.

3. I feel a very high degree of personal ownership for this organization.

4. I feel that this is my company.

5. This is our company.

6. I feel as though I own the company.

7. It is hard for me to think of this organization as mine. (Reversed)

Intention to Stay

1. How likely is it that you will look for a job outside of this organization during the next year? (Reversed)

2. How often do you think about quitting your job at this organization? (Reversed)

3. If it were possible, how much would you like to get a new job? (Reversed)

\section{REFERENCES}

Anderson, J. C., \& Gerbing, D. W. 1988. Structural equation modeling in practice: A review and recommended two-step approach. Psychological Bulletin, 103(3): 411-423.

Bannet, T., \& Kellemanns, F. W. 2006. Are we family and are we treated as family? Nonfamily employees' perceptions of justice in the family firm. Entrepreneurship Theory and Practice, 30(6): 837-854.

Bernhard, F., \& O'Driscoll, M. P. 2011. Psychological ownership in small family-owned businesses: Leadership style and nonfamily-employees' work attitudes and behaviors. Group \& Organization Management, 36(3): 345-384.

Brislin, R. W. 1980. Translation and content analysis of oral and written materials. In H. C. Triandis \& J. W. Berry (Eds), Handbook of cross-cultural psychology: Methodology, Vol. 2: 349-444. Boston, MA: Allyn and Bacon.

Carney, M. 1998. A management capacity constraint? Obstacles to the development of the overseas Chinesc family business. Asia Pacific Journal of Management, 15(2): 137-162.

Chai, S., \& Rhee, M. 2010. Confucian capitalism and the paradox of closure and structural holes in East Asian firms. Management and Organization Revieze, 6(1): 5-29.

Chatman, J. A. 1989. Improving interactional organizational rescarch: A model of personorganization fit. Academy of Management Review, 14(3): 333-349.

Chen, C. C., Chen, Y. R., \& Xin, K. 2004. Guanxi practices and trust in management: A procedural justice perspective. Organization Science, 15(2): 200-209.

Chen, C. C., \& Farh, J. L. 2009. Developments in Chinese leadership: Paternalism and its elaborations, moderations, and alternatives. In M. H. Bond (Ed.), The Oxford handbook of Chinese psychology: 599-622. Oxford, UK: Oxford University Press.

Chen, X. P., Eberly, M. B., Chiang, T. J., Farh, J. L., \& Cheng, B. S. forthcoming. Affective trust in Chinese leaders: Linking paternalistic leadership to cmployec performance.Joumal of Management.

Chen, X. P., \& Peng, S. Q. 2008. Guanxi dynamics: Shifts in the closeness of ties between Chinese coworkers. Management and Organization Revieze, 4(1): 63-80. 
Chen, Y., Friedman, R., Yu, E., Fang, W., \& Lu, X. 2009. Supervisor-subordinate Guanxi: Developing a three-dimensional model and scale. Management and Organization Revieze, 5(3): 375-399.

Chen, Z. X., \& Aryee, S. 2007. Delegation and employee outcomes: An cxamination of the culture context of mediating process in China. Academy of Management Journal, $50(1)$ : $226-238$.

Cheng, B. S., Chou, L. F., Huang, M. P., Farh, J. L., \& Peng, S. C. 2003. A triad model of paternalistic leadership: Evidence from business organizations in mainland China. Indigenous Psychological Research in Chinese Societies, 20: 209-250 (in Chinese).

Cheung, G. W., \& Rensvold, R. B. 2002. Evaluating goodness-of-fit indexes for testing measurement invariance. Structural Equation Modeling, 9(2): 233-255.

Chua, J., Chen, L., Kirkman, B. L., Li, X., Rynes, S., \& Gomez-Mejia, L. 2012. Call for papers: Management and Organization Review special issue on 'Expanding Research on Family Business in China'. Management and Organization Review, 8(1): 249-251.

Corbetta, G., \& Salvato, C. 2004. Self-serving or self-actualizing? Models of man and agency costs in different types of family firms: A commentary on 'Comparing the agency costs of family and non-family firms: Conceptual issues and exploratory evidence'. Entrepreneurship Theory and Practice, 28(4): 355-362.

Davis, J. H., Schoorman, F. D., \& Donaldson, L. 1997. Toward a stewardship theory of management. Academy of Management Revieze, 22(1): 20-47.

Davis, J. H., Frankforter, S., Vollrath, D., \& Hill, V. 2007. An empirical test of stewardship theory. Journal of Business and Leadership: Research, Practice, and Teaching, 3(1): $40-50$.

Davis, J. H., Allen, M. R., \& Hayes, H. D. 2010. Is blood thicker than water? A study of stewardship perceptions in family business. Entrepreneurship Theory and Practice, 34(6): 1093-1166.

De Jong, J., Schalk, R., \& De Cuyper, N. 2009. Balanced versus unbalanced psychological contracts in temporary and permanent employment: Associations with employec attitudes. Management and Organization Revieze, 5(3): 329-351.

Eddleston, K., \& Kellermanns, F. W. 2007. Destructive and productive family relationships: A stewardship theory perspective. Joumal of Business Venturing, 22(4): 545-565.

Farh, J. L., \& Cheng, B. S. 2000. A cultural analysis of paternalistic leadership in Chinese organizations. In J. T. Li, A. S. Tsui \& E. Weldon (Eds), Management and organizations in the Chinese context: $84-127$. London: Macmillan.

Farh, J. L., Tsui, A. S., Xin, K., \& Cheng, B. S. 1998. The influence of relational demography and guanxi: The Chinese case. Organization Science, 9(4): 471-488.

Farh,J. L., Zhong, C. B., \& Organ, D. W. 2004. Organizational citizenship behavior in the people's republic of China. Organization Science, 15(2): 241-253.

Fornell, C., \& Larcker, D. F. 1981. Evaluating structural equation models with unobservable variables and measurement error. Joumal of Marketing Research, 18(1): 39-50.

Fukuyama, F. 1995. Trust. New York: Free Press.

Hernandez, M. 2012. Toward an understanding of the psychology of stewardship. Academy of Management Review, 37(2): 172-193.

Hui, C., Lee, C., \& Rousseau, D. M. 2004. Employment relationships in China: Do workers relate to the organization or to people? Organization Science, 15(2): 232-240.

Hwang, K. K. 1987. Face and favor: The Chinese power game. American Joumal of Sociology, 92(4): 944-974.

Jöreskog, K. G., \& Sörbom, D. 2005. LISREL 8.72 for Windozes. Chicago, IL: Scientific Software International.

Karra, N., Tracey, P., \& Phillips, N. 2006. Altruism and agency in the family firm: Exploring the role of family kinship and ethnicity. Entrepreneurship Theory and Practice, 30(11): $861-878$.

Konovsky, M. A., \& Cropanzano, R. 1991. Perceived fairness of employee drug testing as a predictor of employee attitudes and job performance. Journal of Applied Psychology, 76(5): 698-707.

Li, P. P., Bai, Y., \& Xi, Y. 2012. The contextual antecedents of organizational trust: A multidimensional cross-level analysis. Management and Organization Revieze, 8(2): 371-396.

Luo, J. D. 2011. Guanxi revisited: An exploratory study of familiar ties in a Chinese workplace. Management and Organization Revieze, 7(2): 329-351. 
MacKinnon, D. P., Lockwood, C. M., Hoffman, J. M., West, S. G., \& Sheets, V. 2002. A comparison of methods to test mediation and other intervening variable effects. Psychological Methods, $7(1): 83-104$.

Manz, C. C., \& Sims, H. P.Jr. 1987. Leading workers to lead themselves: The cxternal leadership of self-management work teams. Administrative Science Quarterly, 32(1): 106-128.

Miller, D., \& Le-Breton Miller, I. 2005. Managing for the long run: Lessons in competitive advantage from great family businesses. Boston, MA: Harvard Business School Press.

Pierce, J. L., Kostova, T., \& Dirks, K. T. 2001. Toward a theory of psychological ownership in organizations. Academy of Management Review, 26(2): 298-310.

Pierce, J. L., Jussila, I., \& Cummings, A. 2009. Psychological ownership within the job design context: Revision of the job characteristics model. Journal of Organizational Behavior, 30(4): $477-496$.

Podsakoff, P. M., MacKenzie, S. B., Paine, J. B., \& Bachrach, D. G. 2000. Organizational citizenship behaviors: A critical review of the theoretical and empirical literature and suggestions for future research. Journal of Management, 26(3): 513-563.

Redding, S. G. 1990. The spirit of Chinese capitalism. Berlin: Walter de Gruyter.

Sobel, M. E. 1982. Asymptotic intervals for indirect effects in structural equations models. In S. Lcinhart (Ed.), Sociological methodology: 290-312. San Francisco, CA: Jossey-Bass.

Van Dyne, L.., \& Pierce, J. L. 2004. Psychological ownership and feelings of possession: Thrce field studies predicting employee attitudes and organizational citizenship behavior. Joumal of Organizational Behavior, 25(4): 439-459.

Wasserman, N. 2006. Stewards, agents, and the founder discount: Executive compensation in new venturcs. Academy of Management Joumal, 49(5): 960-976.

Wu, M., Huang, X., Li, C., \& Liu, W. 2011. Perceived interactional justice and trust-in-supervisor as mediators for patcrnalistic leadership. Management and Organization Revieze, 8(1): $97-121$

Ycung, H. W. 2000. Limits to the growth of family owned business? The case of Chinese transnational corporations from Hong Kong. Family Business Revieze, 13(1): 55-70.

Zahra, S. A. 2003. International expansion of U.S. manufacturing family businesses: The effect of ownership and involvement. Journal of Business Venturing, 18(4): 495-5II.

Zhang, J. J., \& Ma, H. 2009. Adoption of professional management in Chinese family business: A multilevel analysis of impetuses and impediments. Asia Pacific Journal of Management, 26(1): 119-139.

Zhang, X. M., \& Bartol, K. M. 2010. Linking empowering leadership and employec creativity: The influence of psychological empowerment, intrinsic motivation, and creative process engagemont. Academy of Management Joumal, 53(1): 107-128.

Hang Zhu (mnszh@mail.sysu.edu.cn) is an associatc professor of entrepreneurship and family business at Sun Yat-sen Business School, Sun Yat-sen University, China. He received his Ph.D. in Strategy and Organization from Sun Yat-sen University, China. His research interests include family business, entreprencurship, and guanxi.

Ghao C. Ghen (chaochen@business.rutgers.edu), Ph.D. SUNY Buffalo, is professor of organization management and global business. He has published articles in premier journals including the Academy of Management Foumal, Academy of Management Review, Administrative Science Quarterly, Journal of Applied Psychology, Organizational Science, Journal of International Business Studies, and Journal of Business Venturing. His current research interests include organizational justice, ethical leadership, guanxi and social networking, and conflict of interest. 
Xinchun Li (mnslxc@mail.sysu.edu.cn) is professor of strategic management and entrepreneurship at Sun Yat-sen Business School and director of the Chinese Family Firm Research Centre at Sun Yat-sen University, China. He is an advisory board member of the International Association of Chinese Management Research, and a member of the editorial advisory board for several Chinese journals. He has published over 60 academic papers in Chinese and international journals such as Management and Organization Review and Asia Pacific Journal of Management. Yinghui Zhou (zyhmaths@163.com) is an Assistant Professor in the Department of Finance, School of Economics at Shanghai University, China. $\mathrm{He}$ received his Ph.D. in Statistics from the Chinese University of Hong Kong (CUHK). His research interests include Bayesian statistics, econometrics, structural equation models, and marketing models.

Manuscript received: August 25, 2010

Final version accepted: August 13, 2012

Accepted by: Soon Ang

\section{SUPPORTING INFORMATION}

Additional Supporting Information may be found in the online version of this article at http://wileyonlinelibrary.com/journal/MORE

Data S1. Supplementary materials 